\title{
Thyroid function tests before prescribing anti-dementia drugs: a retrospective observational study
}

This article was published in the following Dove Press journal:

Clinical Interventions in Aging

\author{
Nobuo Sakata' \\ Yasuyuki Okumura ${ }^{1,2}$ \\ 'Research Department, Institute \\ for Health Economics and Policy, \\ Association for Health Economics \\ Research and Social Insurance and \\ Welfare, Tokyo, Japan; ${ }^{2}$ Department \\ of Psychiatry and Behavioral Science, \\ Tokyo Metropolitan Institute of \\ Medical Science, Tokyo, Japan
}

Purpose: Treatable causes of cognitive dysfunction, such as hypothyroidism, should be excluded by physicians before prescribing anti-dementia drugs. Many clinical guidelines for dementia recommend a thyroid function test (TFT) as one of the standard screening tests for cognitive dysfunction. This study aimed to investigate the national implementation rate of TFTs during the 365 days before the initiation of anti-dementia drugs.

Patients and methods: In this retrospective observational study, using Japan's nationwide claim database, we enrolled $\geq 65$-year-old patients who were newly prescribed anti-dementia drugs between April 2015 and March 2016. The outcome of this study was the implementation of TFTs in the 365 days prior to the index date. We used demographic data, including age, sex, comorbidities, home-based/institutional care, and provider type, as covariates.

Results: We identified 262,279 patients newly prescribed anti-dementia drugs; of these, only $32.6 \%$ underwent TFTs before the initiation of anti-dementia drug treatment. Patients treated in dementia care centers were twice as likely to undergo TFTs as those treated in clinics $(57 \%$ vs $26 \%$; adjusted risk ratio: $2.17 ; 95 \%$ confidence interval: $2.01-2.33$ ).

Conclusion: In Japan, patients with dementia often do not undergo TFTs before being prescribed anti-dementia drugs, particularly in a primary care setting. This suggests that the practice of screening treatable cognitive dysfunction should be audited.

Keywords: cognitive dysfunction, drug treatment, guideline adherence, hypothyroidism

\section{Introduction}

The prevalence of dementia has increased globally. Japan has the highest dementia prevalence among the Organization for Economic Co-operation and Development countries, with 22.3 persons with dementia per 100,000 individuals in the population, as compared to the 17.1 persons in the UK and 11.6 persons in the USA. ${ }^{1}$ This is because the proportion of individuals aged $\geq 65$ years relative to the population was much higher in Japan (27.3\%) than in the UK $(17.9 \%)$ and in the USA $(15.2 \%){ }^{1}$ Physicians are currently prescribing anti-dementia drugs more frequently. However, before initiating such drug treatment, physicians should exclude other, treatable causes of cognitive dysfunction, such as hypothyroidism. ${ }^{2}$

Previous reports have indicated that the prevalence of treatable causes of cognitive dysfunction was $0 \%-30 \%$ among patients with dementia. ${ }^{3-5}$ In most cases of reversible dementia, even adequate treatment cannot result in full recovery from cognitive dysfunction; however, appropriate treatment is considered to contribute to the partial reversal of the condition or preventing symptom progression. ${ }^{3}$ Thus, there is a consensus
Correspondence: Yasuyuki Okumura Department of Psychiatry and Behavioral Science, Tokyo Metropolitan Institute of Medical Science, 2-I-6 Kamikitazawa, Setagaya-ku, Tokyo I56-8506, Japan Tel +8I 368342296

Email yokumura@blue.zero.jp (c) (1) (-) 2018 Sakata and Okumura. This work is published and licensed by Dove Medical Press Limited. The full terms of this license are available at https://www.dovepress.com/terms.php (c) $\mathrm{BY}$ and incorporate the Creative Commons Attribution - Non Commercial (unported, v3.0) License (http://creativecommons.org/licenses/by-nc/3.0/). By accessing the work you hereby accept the Terms. Non-commercial uses of the work are permitted without any further permission from Dove Medical Press Limited, provided the work is properly attributed. For permission for commercial use of this work, please see paragraphs 4.2 and 5 of our Terms (https://www.dovepress.com/terms.php). 
that physicians should identify patients with cognitive dysfunction due to treatable causes at the initial assessment for suspected dementia. ${ }^{6}$

Hypothyroidism is a common treatable cause of cognitive dysfunction and can be treated by thyroid hormone replacement therapy. Therefore, many clinical practice guidelines for dementia recommend a thyroid function test (TFT) as one of the standard screening tests during the initial assessment of dementia. ${ }^{6-8}$ Hypothyroidism could be underdiagnosed in elderly people since the symptoms of hypothyroidism, such as fatigue and cognitive dysfunction, are mostly nonspecific in elderly people and are often attributed to the aging process. ${ }^{9}$ In a previous study, a retrospective chart review of patients with cognitive dysfunction in geriatric clinics revealed that $2.6 \%$ of the patients newly diagnosed with dementia have hypothyroidism. ${ }^{10}$

Although only two studies have investigated the adherence to the clinical practice guideline for dementia in a few memory clinics and secondary health care sectors, no attempt has been made to assess the nationwide adherence to the guideline recommending TFT prior to initial assessment of dementia. ${ }^{11,12}$

Therefore, the present study aimed to examine the national implementation rate of TFTs before newly prescribing anti-dementia drugs and to assess the association between provider adherence and patient characteristics.

\section{Materials and methods}

\section{Data source}

A retrospective observational study was conducted using the nationwide claims database of Japan, called the National Database of Health Insurance Claim Information and Specified Medical Checkups (NDB). The NDB includes all claims issued electronically from $>98 \%$ of medical institutions in Japan and covers $98 \%$ of all patients who have received medical services under Japan's health insurance system. The NDB comprises clinical and procedural information, such as sex, age, patient identification number, institution identification number, diagnostic codes based on the International Statistical Classification of Diseases, 10th Revision (ICD-10), date of laboratory tests, test codes, date of prescription, and drug codes. ${ }^{13,14}$

Our study design was reviewed and approved by the institutional review board at the Institute for Health Economics and Policy. Informed consent was not required for the present study, because the database had data that were completely anonymized of patients' personal information.

\section{Setting}

Japan has 34 million inhabitants who are $\geq 65$ years old and provides universal health insurance coverage to the entire population through employee- and community-based insurance associations. ${ }^{15,16}$ In Japan, patients are free to choose clinics and hospitals; thus, patients with cognitive dysfunction can not only consult primary care physicians but also specialists, without referral. ${ }^{15}$ Primary care physicians are not necessarily required to refer patients with cognitive dysfunction to specialists for evaluation and can initiate anti-dementia drug treatment by themselves.

\section{Patient selection}

In this study, we enrolled patients aged $\geq 65$ years who were newly prescribed anti-dementia drugs between April 2015 and March 2016. The first day of prescription was designated as the index date. These "newly prescribed" patients were defined as those who had not been prescribed anti-dementia drugs for 365 days before the index date. To confirm new users of anti-dementia drugs and receipts of TFTs, we identified those who were enrolled in the database at least 365 days before the index date and excluded those who had a claim reimbursed by bundled payment plans, in which the status of prescription and laboratory testing were not recorded within 365 days before the index date. To focus on patients in whom anti-dementia drugs were initiated shortly after diagnosis of dementia, we excluded patients with a definitive diagnosis of dementia (ICD-10 codes F00-03 and G30-G31) in the period between 365 days and 31 days prior to the index date.

\section{Outcome}

The outcome of the present study was the implementation of TFTs (tests for thyroid-stimulating hormone as well as for free thyroxine) within 365 days before the index date. The medical practice codes for TFTs were 160031710 and 160033310.

\section{Covariates}

Demographic data, such as age, sex, comorbidities, homebased/institutional care, and provider type, were used as covariates. The provider type was classified into three categories: 1) clinics, 2) hospitals, and 3) dementia centers certified by municipalities, based on the placement of specialists. Furthermore, we used the Charlson Comorbidity Index ( 0,1 or 2,3 or more) for evaluating comorbidities, using the patients' ICD-10 diagnostic codes. ${ }^{17}$ 


\section{Statistical analysis}

First, we calculated the incidence proportion of implementation for TFTs. Then, we used a Poisson generalized estimating equation model with the consideration of the correlated data structure (patients clustered within medical facilities) to analyze the association between the implementation of TFTs and each covariate. All covariates were simultaneously entered into the model. Risk ratios (RRs) and their 95\% confidence intervals (CIs) were computed by the exponential of the regression coefficient. ${ }^{18}$ Covariate-adjusted incidence proportions were also estimated from the model. ${ }^{19}$ To obtain crude RRs, we fitted Poisson generalized estimating equation models stratified by each covariate. All data were analyzed using R version 3.4.1 (R Foundation for Statistical Computing, Vienna, Austria).

\section{Results}

We identified 262,279 patients who were newly prescribed anti-dementia drugs in 34,492 medical facilities (Table 1).

Table I Sample characteristics

\begin{tabular}{|c|c|c|}
\hline Characteristics & $\mathbf{n}$ & $\%$ \\
\hline \multicolumn{3}{|l|}{ Setting } \\
\hline Inpatient care & 25,292 & 9.6 \\
\hline Ambulatory care & 236,987 & 90.4 \\
\hline \multicolumn{3}{|l|}{ Provider type } \\
\hline Clinic & $|4|, 489$ & 53.9 \\
\hline Hospital & 106,048 & 40.4 \\
\hline Dementia center & $\mid 4,742$ & 5.6 \\
\hline \multicolumn{3}{|l|}{ Sex } \\
\hline Men & 96,301 & 36.7 \\
\hline Women & 165,978 & 63.3 \\
\hline \multicolumn{3}{|l|}{ Age, years } \\
\hline $65-69$ & 9,066 & 3.5 \\
\hline $70-74$ & 23,175 & 8.8 \\
\hline $75-79$ & 50,054 & 19.1 \\
\hline $80-84$ & 77,389 & 29.5 \\
\hline$\geq 85$ & 102,595 & 39.1 \\
\hline \multicolumn{3}{|l|}{ Charlson index } \\
\hline 0 & 8,267 & 3.2 \\
\hline I & 83,116 & 31.7 \\
\hline 2 & 73,657 & 28.1 \\
\hline$\geq 3$ & 97,239 & 37.1 \\
\hline \multicolumn{3}{|c|}{ Use of home-based care } \\
\hline None & 253,224 & 96.5 \\
\hline Home & 4,926 & 1.9 \\
\hline Institution & 4,129 & 1.6 \\
\hline \multicolumn{3}{|c|}{ Type of anti-dementia drugs } \\
\hline Donepezil & 162,980 & 62.1 \\
\hline Galantamine & 38,004 & 14.5 \\
\hline Memantine & 35,963 & 13.7 \\
\hline Rivastigmine & 28,371 & 10.8 \\
\hline Use of antipsychotics & 17,393 & 6.6 \\
\hline
\end{tabular}

Table 2 Implementation rate of thyroid function tests

\begin{tabular}{|c|c|c|c|c|}
\hline \multirow[t]{2}{*}{ Characteristics } & \multicolumn{2}{|c|}{ Crude } & \multicolumn{2}{|c|}{ Adjusted $^{\S}$} \\
\hline & Risk & $\begin{array}{l}\text { Risk ratio } \\
(95 \% \mathrm{Cl})\end{array}$ & Risk & $\begin{array}{l}\text { Risk ratio } \\
(95 \% \mathrm{Cl})\end{array}$ \\
\hline Total & 0.326 & & & \\
\hline \multicolumn{5}{|l|}{ Sex } \\
\hline Men (reference) & 0.309 & & 0.357 & \\
\hline Women & 0.336 & $1.09(1.07-1.10)$ & 0.412 & $1.15(1.14-1.17)$ \\
\hline \multicolumn{5}{|l|}{ Age, years } \\
\hline $65-69$ & 0.394 & & 0.424 & \\
\hline \multicolumn{5}{|l|}{ (reference) } \\
\hline $70-74$ & 0.372 & $0.94(0.92-0.97)$ & 0.409 & $0.96(0.94-0.99)$ \\
\hline $75-79$ & 0.366 & $0.93(0.90-0.96)$ & 0.402 & $0.95(0.92-0.98)$ \\
\hline 80-84 & 0.339 & $0.86(0.83-0.89)$ & 0.376 & $0.89(0.86-0.91)$ \\
\hline$\geq 85$ & 0.281 & $0.7 \mathrm{I}(0.69-0.74)$ & 0.315 & $0.74(0.72-0.77)$ \\
\hline \multicolumn{5}{|l|}{ Charlson index } \\
\hline 0 (reference) & 0.271 & & 0.334 & \\
\hline I & 0.321 & $1.19(1.12-1.26)$ & 0.385 & 1.15 (I.09-1.22) \\
\hline 2 & 0.312 & 1.15 (1.08-1.22) & 0.391 & $1.17(1.11-1.24)$ \\
\hline$\geq 3$ & 0.347 & $1.28(1.21-1.36)$ & 0.430 & $1.29(1.22-1.36)$ \\
\hline \multicolumn{5}{|c|}{ Use of home-based care } \\
\hline None & 0.328 & & 0.378 & \\
\hline \multicolumn{5}{|l|}{ (reference) } \\
\hline Home & 0.299 & $0.91(0.87-0.96)$ & 0.407 & $1.08(1.02-1.13)$ \\
\hline Institution & 0.272 & $0.83(0.78-0.88)$ & 0.366 & $0.97(0.91-1.02)$ \\
\hline \multicolumn{5}{|l|}{ Provider type } \\
\hline Clinic & 0.258 & & 0.261 & \\
\hline (reference) & & & & \\
\hline Hospital & 0.383 & $1.49(1.43-1.55)$ & 0.382 & $\mathrm{I} .47(\mathrm{I} .4 \mathrm{I}-\mathrm{I} .53)$ \\
\hline Dementia center & 0.571 & $2.21(2.06-2.38)$ & 0.565 & $2.17(2.01-2.33)$ \\
\hline
\end{tabular}

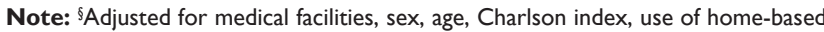
care, and provider type.

The annual number of new users per facility ranged from 1 to 450 with a median of 3 (interquartile range: $1-7$ ). Our study population predominantly comprised women and outpatients, and $54 \%$ of the patients were treated in clinics, whereas $5.6 \%$ of the patients were treated in dementia centers. TFTs were performed for $32.6 \%$ (95\% CI: $32.5-32.8)$ of the enrolled patients before their first prescription.

Table 2 shows the crude and adjusted RRs (aRRs) for the associations between the implementation of TFTs and covariates. Patients treated in hospitals were 1.5 times more likely to undergo TFTs than those treated in clinics (38\% vs $26 \%$; aRR: $1.47,95 \%$ CI: 1.41-1.53). Patients treated in dementia care centers were twice as likely to undergo TFTs as those treated in clinics ( $57 \%$ vs $26 \%$; aRR: $2.17,95 \%$ CI: $2.01-2.33$ ). Patients aged $\geq 85$ years were $25 \%$ less likely to undergo TFTs than patients aged $65-69$ years (28\% vs 39\%; aRR: 0.74; 95\% CI: 0.72-0.77). Older patients were less likely to undergo TFTs.

\section{Discussion}

To the best of our knowledge, this is the first study to evaluate the nationwide implementation rate of TFTs for the initial assessment of dementia. In Japan, $>60 \%$ of patients with 
dementia did not undergo TFTs during the 365-day period before being prescribed anti-dementia drugs.

The difference between the implementation rates for the patients treated in clinics and dementia centers could be attributed to the expertise of physicians in dementia centers, since they are better acquainted with the diagnosis of dementia than the majority of primary care physicians who examine elderly patients in clinics. ${ }^{20}$ A previous study reported that the accuracy of dementia diagnosis by primary care physicians was not as good as that by geriatric experts. ${ }^{21}$ Furthermore, the lack of implementation of TFTs by physicians in clinics could be related to some reasons other than inadequate knowledge. Prior research has suggested that lack of resources and organizational constraints, such as an insufficient number of staff members, were barriers to the implementation of clinical guidelines among primary care physicians. ${ }^{22,23}$ Further research is warranted to elucidate the reason for the low implementation rate of TFTs in the primary care setting. In addition, the implementation rate of other recommended tests such as brain imaging remains unclear and calls for further investigations.

In the present study, older patients were less likely to undergo TFTs. This may be because physicians often assume that cognitive dysfunction should be caused by primary dementia, such as Alzheimer's disease, given that the prevalence of primary dementia increases with age. ${ }^{24}$ Another possible explanation is that physicians generally tend to prioritize avoiding potential harm caused by unnecessary tests and treatments in elderly patients and therefore refrain from requiring laboratory tests for elderly individuals more than they would for younger patients.

Hypothyroidism is more likely to occur in the elderly than in the young and is often less symptomatic in these individuals. ${ }^{9}$ As the study of the Framingham cohort reported that $4.4 \%$ of the unselected population of elderly subjects ( $>60$ years) had thyroid deficiency, elderly patients with cognitive dysfunction are more likely to have thyroid dysfunction than the general elderly population, given that cognitive dysfunction is one of the symptoms in hypothyroidism. ${ }^{9,25,26}$ Appropriate thyroid hormone replacement can reverse the symptoms of hypothyroidism; not only cognitive dysfunction, but also other symptoms, such as fatigue and muscle weakness, for which anti-dementia drugs are not indicated. In contrast, untreated hypothyroidism can progress to severe state called myxedema. It is impossible to differentiate hypothyroidism without laboratory tests due to its nonspecific symptoms. In addition, TFTs can be performed concurrently with basic blood tests, such as complete blood counts, without causing any additional discomfort to patients. Therefore, thyroid function should be assessed for patients with dementia even if they do not present the typical symptoms of hypothyroidism, in accordance with the clinical practice guidelines for dementia. ${ }^{2,6,7}$

This study has several limitations. First, our study population was selected only from patients with dementia who were treated with anti-dementia drugs. This population might be more likely to undergo the screening tests for the dementia work-up than those who have not been prescribed anti-dementia drugs. Second, because of our study design, we could not assess the implementation of TFTs $>1$ year before the diagnosis of dementia. It is possible that cognitive function was followed for more than 1 year in some patients, without a diagnosis of dementia after the dementia work-up, which could have led to an underestimation of the implementation rate. Third, we excluded those who had a claim reimbursed by a bundled payment plan, because of the insufficient information of the prescription and laboratory tests. Accordingly, the generalizability of this study is limited.

\section{Conclusion}

Patients with dementia often do not undergo TFTs before being prescribed anti-dementia drugs, particularly in a primary care setting in Japan. The practice of screening treatable cognitive dysfunction at the time of presentation should be audited.

\section{Acknowledgments}

This study was supported by grants from the Japan Agency for Medical Research and Development (No 16dk0207024h0001). The sponsors of this study had no role in the design and conduct of the study; collection, management, analysis, or interpretation of the data; preparation, review, or approval of the manuscript; or the decision to submit the manuscript for publication. We would like to express our appreciation to Editage for providing editorial assistance.

\section{Disclosure}

During the past 3 years, YO received personal fees from Janssen Pharmaceuticals, Inc., the Medical Technology Association, and Cando Inc. He has also received research grants from the Japan Agency for Medical Research and Development; Ministry of Health, Labor, and Welfare; Japan Society for the Promotion of Science; Institute for Health Economics and Policy; and Mental Health and Morita 
Therapy. The authors report no other conflicts of interest in this work.

\section{References}

1. OECD. Health at a Glance 2017. Paris: OECD Publishing, 2017.

2. Knopman DS, DeKosky ST, Cummings JL, et al. Practice parameter: diagnosis of dementia (an evidence-based review). Report of the Quality Standards Subcommittee of the American Academy of Neurology. Neurology. 2001;56(9):1143-1153.

3. Clarfield AM. The decreasing prevalence of reversible dementias: an updated meta-analysis. Arch Intern Med. 2003;163(18):2219-2229.

4. Djukic M, Wedekind D, Franz A, Gremke M, Nau R. Frequency of dementia syndromes with a potentially treatable cause in geriatric in-patients: analysis of a 1-year interval. Eur Arch Psychiatry Clin Neurosci. 2015;265(5):429-438.

5. Harisingani R. Where are the reversible dementias? J Am Geriatr Soc. 2005;53(6):1066-1068.

6. Ngo J, Holroyd-Leduc JM. Systematic review of recent dementia practice guidelines. Age Ageing. 2015;44(1):25-33.

7. Hort J, O'Brien JT, Gainotti G, et al. EFNS guidelines for the diagnosis and management of Alzheimer's disease. Eur J Neurol. 2010; 17(10):1236-1248.

8. Karlawish JH, Clark CM. Diagnostic evaluation of elderly patients with mild memory problems. Ann Intern Med. 2003;138(5):411-419.

9. Bensenor IM, Olmos RD, Lotufo PA. Hypothyroidism in the elderly: diagnosis and management. Clin Interv Aging. 2012;7:97-111.

10. Muangpaisan W, Petcharat C, Srinonprasert V. Prevalence of potentially reversible conditions in dementia and mild cognitive impairment in a geriatric clinic. Geriatr Gerontol Int. 2012;12(1):59-64.

11. Phung TK, Andersen BB, Kessing LV, Mortensen PB, Waldemar G. Diagnostic evaluation of dementia in the secondary health care sector. Dement Geriatr Cogn Disord. 2009;27(6):534-542.

12. Turro-Garriga O, Calvo-Perxas L, Vilalta-Franch J, et al. Adherence to clinical practice guidelines during dementia work-up in a real-world setting: a study from the Registry of Dementias of Girona. J Alzheimers Dis. 2017;59(3):997-1007.

13. Kubo S, Noda T, Myojin T, et al. National Database of Health Insurance Claims and Specific Health Checkups of Japan (NDB): outline and patient-matching technique. bioRxiv. Available from: https:// www.biorxiv.org/content/early/2018/04/02/280008.full.pdf. Accessed April 5, 2018.
14. Okumura Y, Sakata N, Takahashi K, Nishi D, Tachimori H. Epidemiology of overdose episodes from the period prior to hospitalization for drug poisoning until discharge in Japan: An exploratory descriptive study using a nationwide claims database. J Epidemiol. 2017; 27(8):373-380.

15. Sakamoto H, Rahman M, Nomura S, et al. Japan Health System Review. Health Syst Transit. 2018;8(1):1-248.

16. Statistic Bureau, Ministry of Internal Affairs and Communications. Population Estimates. Available from: http://www.stat.go.jp/data/jinsui/ pdf/201802.pdf. Accessed February 28, 2018.

17. Charlson ME, Pompei P, Ales KL, MacKenzie CR. A new method of classifying prognostic comorbidity in longitudinal studies: development and validation. J Chronic Dis. 1987;40(5):373-383.

18. Knol MJ, Le Cessie S, Algra A, Vandenbroucke JP, Groenwold RH. Overestimation of risk ratios by odds ratios in trials and cohort studies: alternatives to logistic regression. CMAJ. 2012;184(8):895-899.

19. Lenth RV. Least-squares means: the R Package lsmeans. J Stat Software. 2016;69(1):33.

20. Kirson NY, Desai U, Ristovska L, et al. Assessing the economic burden of Alzheimer's disease patients first diagnosed by specialists. $B M C$ Geriatr. 2016;16:138.

21. Parmar J, Dobbs B, McKay R, et al. Diagnosis and management of dementia in primary care: exploratory study. Can Fam Physician. 2014; 60(5):457-465.

22. Lugtenberg M, Burgers JS, Besters CF, Han D, Westert GP. Perceived barriers to guideline adherence: a survey among general practitioners. BMC Fam Pract. 2011;12:98.

23. Lugtenberg M, Zegers-van Schaick JM, Westert GP, Burgers JS. Why don't physicians adhere to guideline recommendations in practice? An analysis of barriers among Dutch general practitioners. Implement Sci. 2009;4:54.

24. Winblad B, Amouyel P, Andrieu S, et al. Defeating Alzheimer's disease and other dementias: a priority for European science and society. Lancet Neurol. 2016;15(5):455-532.

25. Tan ZS, Beiser A, Vasan RS, et al. Thyroid function and the risk of Alzheimer disease: the Framingham Study. Arch Intern Med. 2008; 168(14):1514-1520.

26. Tan ZS, Vasan RS. Thyroid function and Alzheimer's disease. J Alzheimers Dis. 2009;16(3):503-507.
Clinical Interventions in Aging

\section{Publish your work in this journal}

Clinical Interventions in Aging is an international, peer-reviewed journal focusing on evidence-based reports on the value or lack thereof of treatments intended to prevent or delay the onset of maladaptive correlates of aging in human beings. This journal is indexed on PubMed Central, MedLine,

\section{Dovepress}

CAS, Scopus and the Elsevier Bibliographic databases. The manuscript management system is completely online and includes a very quick and fair peer-review system, which is all easy to use. Visit http://www.dovepress. $\mathrm{com} /$ testimonials.php to read real quotes from published authors. 